\title{
The effect of Al-doping on $\mathrm{ZnO}$ nanoparticles applied as catalyst support $\dagger$
}

\author{
Malte Behrens, ${ }^{* a b}$ Giulio Lolli, ${ }^{a}$ Nelli Muratova, ${ }^{a}$ Igor Kasatkin, ${ }^{a}$ \\ Michael Hävecker, ${ }^{a c}$ Raoul Naumann d'Alnoncourt, ${ }^{a d}$ Oksana Storcheva, ${ }^{e}$ \\ Klaus Köhler, ${ }^{e}$ Martin Muhler ${ }^{d}$ and Robert Schlögl ${ }^{a}$
}

Received 23rd May 2012, Accepted 7th June 2012

DOI: $10.1039 / \mathrm{c} 2 \mathrm{cp} 41680 \mathrm{~h}$

A pure $\mathrm{ZnO}$ sample and a sample containing $3 \mathrm{~mol} \% \mathrm{Al}$ were prepared by (co)-precipitation as model materials for the oxidic support phase in $\mathrm{Cu} / \mathrm{ZnO} / \mathrm{Al}_{2} \mathrm{O}_{3}$ methanol synthesis catalysts. The samples were characterized with respect to their crystal, defect and micro-structure using various methods (XRD, TEM, XPS, UV-vis spectroscopy, EPR, NMR). It was found that a significant fraction of the $\mathrm{Al}$ is incorporated into the $\mathrm{ZnO}$ lattice and enhances the defect chemistry of the material. The defect structure, however, was not stable under reducing conditions as applied in catalytic reactions. $\mathrm{Al}$ ions migrated towards the surface of the $\mathrm{ZnO}$ nanoparticles leading to formation of an Al-rich shell and an Al-depleted core. This process proceeds during the first 10-20 hours on stream and is associated with strong modification of the optical bandgap energy and the EPR signal of donor sites present in $\mathrm{ZnO}$.

\section{Introduction}

$\mathrm{ZnO}$ is a wide bandgap semiconductor material and isomorphous partial substitution of $\mathrm{Zn}^{2+}$ in the wurtzite lattice of $\mathrm{ZnO}$ (doping) by other cations is of interest e.g. for electronic applications. These applications have generated strong research activity on defective or doped $\mathrm{ZnO}$ and its electronic properties. ${ }^{1-3}$ Trivalent cations like $\mathrm{Al}^{3+}$ as dopants generate excess positive charge and promote $n$-type semi-conductivity. $\mathrm{ZnO}$ is also an interesting material for synthetic material science and catalytic applications. Directed synthesis of $\mathrm{ZnO}$ nano-structures is possible ${ }^{4}$ and, recently, synthesis by precipitation of $\mathrm{ZnO}$ nanopowder with high surface area was reported. ${ }^{5}$ In the field of model catalysis, surface studies on $\mathrm{ZnO}$ single crystals and their adsorption properties are available. ${ }^{6}$ For industrial catalysis, the $\mathrm{Zn}-\mathrm{Al}$ substitution in $\mathrm{ZnO}$ is of special interest, because $\mathrm{ZnO} / \mathrm{Al}_{2} \mathrm{O}_{3}$ is the oxidic phase in $\mathrm{Cu} / \mathrm{ZnO} / \mathrm{Al}_{2} \mathrm{O}_{3}$ catalyst employed for

${ }^{a}$ Fritz Haber Institute of the Max Planck Society, Department of Inorganic Chemistry, Faradayweg 4-6, 14195 Berlin, Germany. E-mail: behrens@fhi-berlin.mpg.de; Fax: + 4930 8413-4405;

Tel: + $49308413-4408$

${ }^{b}$ Ertl Center for Electrochemistry \& Catalysis, Gwangju Institute of Science and Technology (GIST), Gwangju 500-712, South Korea

${ }^{c}$ Division Solar Energy Research, Elektronenspeicherring BESSY II, Helmholtz-Zentrum Berlin für Materialien und Energie,

Albert-Einstein-Strasse 15, 12489 Berlin, Germany

${ }^{d}$ Ruhr-Universität Bochum, Industrial Chemistry, Universitätsstraße 150, 44781 Bochum, Germany

${ }^{e}$ Technische Universität München, Department Chemie, Anorganische Chemie, Lichtenbergstraße 4, 85747 Garching, Germany

$\dagger$ Electronic supplementary information (ESI) available. See DOI: $10.1039 / \mathrm{c} 2 \mathrm{cp} 41680 \mathrm{~h}$ methanol synthesis and steam reforming of methanol. Even though it is generally accepted that the active center for methanol synthesis is located on metallic $\mathrm{Cu}$, it is clear that the role of $\mathrm{ZnO}$ and $\mathrm{Al}_{2} \mathrm{O}_{3}$ goes beyond that of a mere physical support. ${ }^{7-9}$ For $\mathrm{Cu}$ and $\mathrm{ZnO}$ a synergetic effect is discussed, while $\mathrm{Al}_{2} \mathrm{O}_{3}$, which is typically present in amounts of $5-10 \mathrm{~mol} \%$, acts as a promoter and leads to higher thermal stability as well as higher intrinsic activity of the $\mathrm{Cu}$ surface compared to binary $\mathrm{CuZn}$ catalysts. This promoting effect is not well understood yet.

$\mathrm{ZnO}$ alone may also be active in methanol synthesis from syngas $\left(\mathrm{H}_{2} / \mathrm{CO} / \mathrm{CO}_{2}\right.$ mixtures), but the reaction requires higher temperatures and pressures compared to the $\mathrm{Cu}$-containing systems. The methanol synthesis over $\mathrm{ZnO}$ from $\mathrm{H}_{2} / \mathrm{CO}$ mixtures was recently related to the presence of oxygen vacancies in defective $\mathrm{ZnO}_{1-x}$ nanoparticles. ${ }^{10,11}$ These defects are also thought to play a major role in $\mathrm{Cu} / \mathrm{ZnO}$-based catalysts, as partially reduced $\mathrm{ZnO}_{x}$ species were shown to migrate onto the $\mathrm{Cu}$ particles under a reducing atmosphere, resulting in strong metal support interaction (SMSI). This in situ formed surface ensemble is believed to represent the active sites for methanol synthesis. ${ }^{7,12,13}$ Thus, the defect and substitution chemistry of $\mathrm{ZnO}$ is highly relevant for catalytic $\mathrm{Cl}$ conversions over $\mathrm{ZnO}$ containing catalysts. Interestingly, only a few studies report about the important binary $\mathrm{Zn}-\mathrm{Al}$ oxide systems from a catalytic point of view. A comprehensive study of the surface properties and defect chemistry of a highly dispersed $\mathrm{ZnAl}_{2} \mathrm{O}_{4}$ on $\gamma-\mathrm{Al}_{2} \mathrm{O}_{3}$ catalyst, i.e. on the Al-rich side of the $\mathrm{Zn}-\mathrm{Al}$ oxide system, is available. ${ }^{14,15}$ Recently, $\mathrm{ZnO}-\mathrm{Al}_{2} \mathrm{O}_{3}$ catalysts have been reported to be active for the methanol steam reforming reaction at high temperatures ${ }^{16}$ and the role of $\mathrm{Al}$ dopants in $\mathrm{ZnO}$ for $\mathrm{CO}$ 


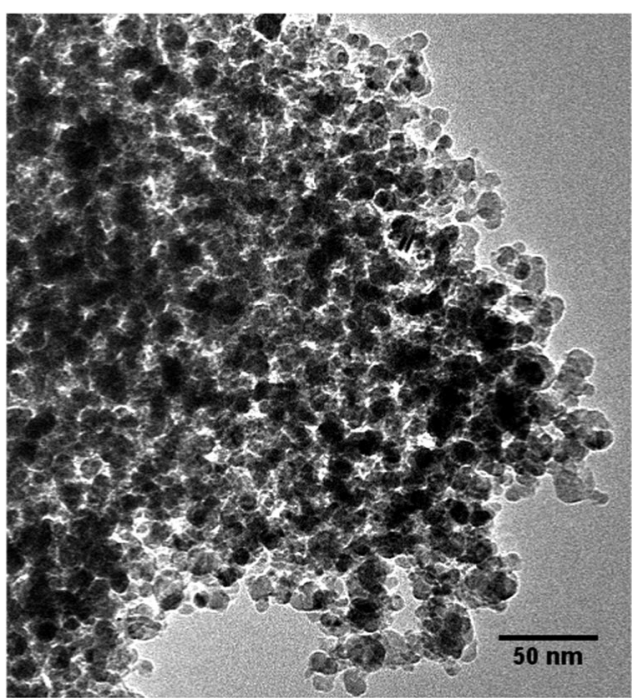

Fig. 1 TEM image of a technical $\mathrm{Cu} / \mathrm{ZnO} / \mathrm{Al}_{2} \mathrm{O}_{3}$ catalyst.

oxidation has been investigated. ${ }^{17}$ In another recent paper Miao et al. ${ }^{18}$ reported the incorporation of low amounts of up to $4 \mathrm{~mol} \% \mathrm{Al}$ into the $\mathrm{ZnO}$ lattice for samples prepared at conditions applied for $\mathrm{Cu} / \mathrm{ZnO} / \mathrm{Al}_{2} \mathrm{O}_{3}$ catalyst synthesis. This was evidenced by ${ }^{27} \mathrm{Al}$ MAS-NMR measurements, showing that $\mathrm{Al}$ occupied well defined tetrahedral sites in the $\mathrm{ZnO}$ lattice. This $\mathrm{Al}$ species was not observed at higher $\mathrm{Al}$ contents, where segregated phases like $\mathrm{ZnAl}_{2} \mathrm{O}_{4}$ or $\gamma-\mathrm{Al}_{2} \mathrm{O}_{3}$ were detected. Herein, we address the defect chemistry and modifications of the electronic structure of $\mathrm{ZnO}$ related to this incorporation of $\mathrm{Al}$ for samples prepared under conditions relevant for bulk catalyst synthesis, i.e. by co-precipitation from aqueous solutions and subsequent mild thermal treatment.

It is noted that industrial methanol synthesis catalyst is not a classical supported system with low metal loading, but a so-called bulk catalyst. Due to solid state chemical constraints of the precursor material, ${ }^{19}$ the optimal $\mathrm{Cu}: \mathrm{Zn}$ ratio in these catalysts is near $70: 30^{20}$ and the $\mathrm{ZnO}$ phase is typically present, like the $\mathrm{Cu}$ phase, in the form of aggregated nano-particles ${ }^{21,22}$ and not as an extended continuous support. Fig. 1 is a representative TEM image of the nanostructured $\mathrm{Cu}-\mathrm{ZnO}$ aggregates showing the intimate interface contact of metal and oxide nanoparticles. The $\mathrm{Cu}$ and $\mathrm{ZnO}$ phases are typically prepared simultaneously in course of catalyst precursor co-precipitation and subsequent thermal treatment. In this work, however, we have studied $\mathrm{Cu}$-free $\mathrm{Al}$-modified $\mathrm{ZnO}$ as a model support for the ternary catalyst system. Samples were prepared according to the established recipes for $\mathrm{Cu} / \mathrm{ZnO} / \mathrm{Al}_{2} \mathrm{O}_{3}$ catalyst preparation, ${ }^{23}$ but without adding $\mathrm{Cu}$. This approach, previously applied by Miao et al., allowed application of characterization techniques like optical spectroscopy, ${ }^{27} \mathrm{Al}-\mathrm{MAS}-\mathrm{MNR}$ and EPR, which in the case of real catalyst only give little or very complex information due to the dark color and paramagnetism of the $\mathrm{CuO}$ component.

\section{Experimental}

\section{Preparation of the $\mathrm{ZnO} / \mathrm{Al}_{2} \mathrm{O}_{3}$ support}

Two $\mathrm{ZnO} / \mathrm{Al}_{2} \mathrm{O}_{3}$ supports were prepared by $\mathrm{pH}$-controlled coprecipitation in an automated reactor (LabMax from
Mettler-Toledo), similar to industrially prepared catalysts. ${ }^{23}$ Appropriate amounts of $\mathrm{Zn}\left(\mathrm{NO}_{3}\right)_{2} \cdot 6 \mathrm{H}_{2} \mathrm{O}$ and $\mathrm{Al}\left(\mathrm{NO}_{3}\right)_{3} \cdot 9 \mathrm{H}_{2} \mathrm{O}$ were dissolved in $300 \mathrm{ml}$ of water to obtain a $1.5 \mathrm{M}$ solution of the metal salts. This solution was added to the reactor containing $500 \mathrm{ml}$ of water at a constant rate of $15 \mathrm{ml} \mathrm{min}^{-1}$. The proper amount of $\mathrm{Na}_{2} \mathrm{CO}_{3}$ solution $(1.5 \mathrm{M})$ was automatically added to keep the $\mathrm{pH}$ constant at neutrality. Precipitation was done at a temperature of $65{ }^{\circ} \mathrm{C}$ and followed by ageing for $2 \mathrm{~h}\left(65{ }^{\circ} \mathrm{C}\right.$, $\mathrm{pH}$ 7). The solid was then filter-collected and washed several times by re-dispersion in 11 of water until the conductivity of the washing medium was below $0.1 \mathrm{mS} \mathrm{cm}^{-1}$.

The precipitate was then dried by a strong dry air flow at $30{ }^{\circ} \mathrm{C}$ for $72 \mathrm{~h}$, followed by calcination for $4 \mathrm{~h}$ in static air at $320{ }^{\circ} \mathrm{C}\left(2 \mathrm{~K} \mathrm{~min}^{-1}\right)$. Materials obtained at other calcination temperatures $\left(265\right.$ and $375{ }^{\circ} \mathrm{C}$ ) are described in the ESI. $\dagger$ The typical batch size of the material after this procedure was approximately $30 \mathrm{~g}$. The $\mathrm{Zn}: \mathrm{Al}$ ratios were $100: 0$ (pure $\mathrm{ZnO}$ ) and 97 : 3 (Al-doped $\mathrm{ZnO}$ ).

\section{Characterization methods}

XRD data were collected using a Bruker AXS D8 Advance Theta-theta diffractometer in Bragg-Brentano geometry, equipped with a $\mathrm{Cu}$ anode, a secondary graphite monochromator $\left(\mathrm{CuK} \alpha_{1+2}\right.$ radiation) and a scintillation counter. Patterns were recorded between 10 and $100^{\circ} 2 \theta$ with a step width of $0.02^{\circ}$ and a counting time of $15 \mathrm{~s}$ per step. The diffractograms were analyzed by full pattern fitting using the software Topas ${ }^{24}$ (Bruker AXS) to extract the lattice parameters.

A Philips CM200FEG microscope operated at $200 \mathrm{kV}$ and equipped with a field emission gun, the Gatan imaging filter, and an energy-dispersive X-ray (EDX) analyser was used for TEM investigations. The coefficient of spherical aberration was $C_{\mathrm{s}}=1.35 \mathrm{~mm}$, and the information limit was better than $0.18 \mathrm{~nm}$. High-resolution images with a pixel size of $0.016 \mathrm{~nm}$ were taken at the magnification of $1083000 \times$ with a CCD camera, and selected areas were processed to obtain the power spectra (square of the Fourier transform of the image), which were used for measuring interplanar distances $( \pm 0.5 \%)$ and angles $\left( \pm 0.5^{\circ}\right)$ for phase identification.

Continuous-wave EPR spectra were recorded on a $J E O L$ $J E S$ - $R E 2 X$ system at $\mathrm{X}$-band frequency at a temperature of $285 \mathrm{~K}$. The spectra were measured at a microwave frequency of $c a .9 \mathrm{GHz}$ with a microwave power of $5 \mathrm{~mW}$, with modulation amplitude of $0.4 \mathrm{mT}$, sweep time $4 \mathrm{~min}$, sweep width $50 \mathrm{mT}$, time constant $0.1 \mathrm{~s}$ and a modulation frequency of $100 \mathrm{kHz}$. The microwave frequency was measured with a microwave frequency counter Advantest R5372. The temperature was monitored with a JEOL ES DVT2 temperature controller equipped with a calibrated thermocouple. The samples were subjected to different heat treatments in an inert or reducing atmosphere in the EPR tube (constructed as a flow reactor, where the gases flow through the fixed sample bed), cooled to room temperature in the gas flow without contact to air before the EPR spectra were recorded.

UV-VIS spectroscopy was recorded in a Perkin-Elmer Lambda 650 High Performance Spectrometer equipped with a Harrick Praying Mantis diffuse reflectance attachment and a high temperature (up to $650{ }^{\circ} \mathrm{C}$ ) in situ cell, which was connected 
to a gas delivery system. The band gap energy was calculated by linear extrapolation of the function $\left[F\left(R_{\infty}\right) h \nu\right]^{1 / 2}$ versus $h \nu$ to 0 , as suggested by Weber ${ }^{25}$ and Iglesia and co-workers. ${ }^{26-28}$ This procedure results from a linearization of the theory of direct and indirect band gap transitions in semiconductors ${ }^{29}$ and is explained in detail by Barton et al. ${ }^{28}$

One-dimensional ${ }^{27} \mathrm{Al}$-MAS-NMR spectra were measured with a Bruker ASX400 spectrometer operating at a frequency of $104.26 \mathrm{MHz}$ and a spinning speed of $8.5 \mathrm{kHz}$. BET surface area was calculated from $\mathrm{N}_{2}$ absorption in a Quantachrome 6 port BET system. Prior to the measurements the samples were evacuated for $2 \mathrm{~h}$ at $100{ }^{\circ} \mathrm{C}$.

Environmental XPS and NEXAFS experiments were performed at the ISISS beamline of the synchrotron BESSY-II in Berlin, Germany. The station was equipped with a differential pumping stage allowing a background pressure of reactive atmospheres up to 1 mbar. More details can be found in ref. 30 and 31. The surface composition was calculated from the $\mathrm{Zn} 3 \mathrm{p}$ and $\mathrm{Al} 2 \mathrm{p}$ core level spectra using elemental photoelectron cross sections and asymmetry factors taken from Yeh and Lindau. ${ }^{32}$ For the calculation all spectra have been normalized by the storage ring current and the energy dependent incident monochromatic photon flux which has been determined prior to the measurements using a gold foil with known quantum efficiency. The data obtained have been corrected for higher diffraction orders of the grating monochromator that contribute to the background but not to the peak intensity in XPS. The photon energy was $260 \mathrm{eV}$ for both the $\mathrm{Zn} 3 \mathrm{p}$ and $\mathrm{Al} 2 \mathrm{p}$ core levels resulting in a kinetic energy of about $180 \mathrm{eV}$ of the released photon electrons.

NEXAFS spectra at the Al K-edge were recorded in the total electron yield mode enhanced by additional electrons created by ionization of the gas phase above the sample (conversion electron yield).

\section{Results and discussion}

The starting point of this study was the paper of Miao et al., ${ }^{18}$ reporting on $\mathrm{Al}$ incorporation into the crystal lattice of $\mathrm{ZnO}$ for $\mathrm{Zn}: \mathrm{Al}$ ratios near $96: 4$. In addition to evidence from XRD and NMR, an intensification of the yellowish color was reported for samples with an $\mathrm{Al}$ content around $4 \mathrm{~mol} \%$. This triggered us to study this series of samples with UV-vis spectroscopy to determine the optical band gap as a function of $\mathrm{Al}$ content. The results are shown in Fig. 2. It can be seen that the pure $\mathrm{ZnO}$ sample exhibits an optical band gap of $3.12 \mathrm{eV}$, which is at the lower end of the range typically reported for $\mathrm{ZnO}$ in the literature. A significant reduction of the band separation is observed with increasing $\mathrm{Al}$ content. This is in agreement with the change of the sample color from white to yellowish. Interestingly, the bandgap increases again as the $\mathrm{Al}$ content is increased beyond $4 \%$ and a sharp minimum in bandgap energy is formed around the composition of maximal $\mathrm{Al}$ incorporation into the $\mathrm{ZnO}$ lattice. It is noted that bi-phasic samples are present for $\mathrm{Al}$ contents $>4 \%$ as at these concentrations $\mathrm{Al}$ is preferentially located in segregated phases and not in $\mathrm{ZnO}^{18}$ Such a second phase was not represented in the optical spectra in the form of a second distinguishable absorption. Thus, the values for [Al] $>4 \%$ given in Fig. 2 have to be interpreted with care. However, the trend of decreasing

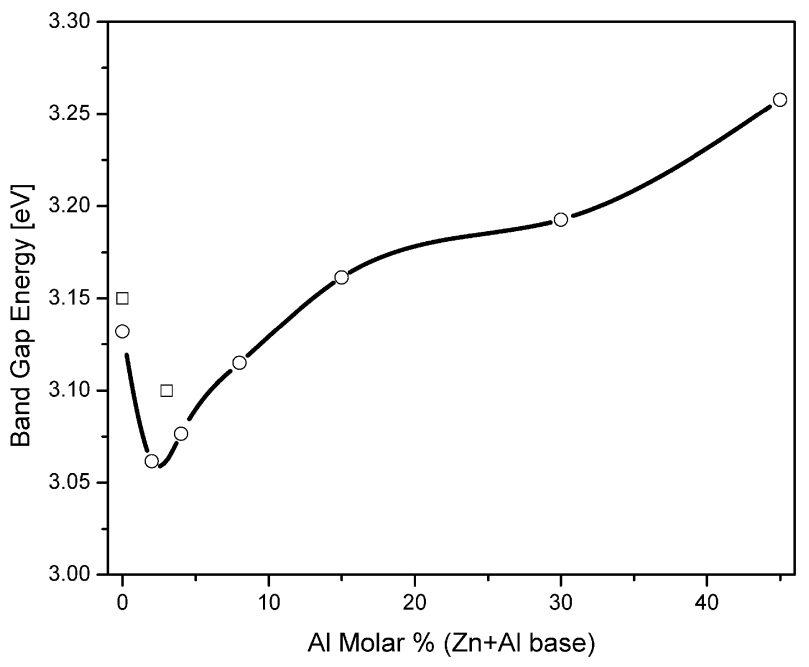

Fig. 2 Optical bandgap energies of the samples series prepared by Miao et al. ${ }^{18}$ (spheres) and of this study (squares).

band gap energy with Al-incorporation at $[\mathrm{Al}]<4 \%$ and the minimum in the band gap energy for the maximal $\mathrm{Al}$ incorporation in $\mathrm{ZnO}$ is clearly seen. Thus, the electronic structure of $\mathrm{ZnO}$ is significantly affected by $\mathrm{Al}$ incorporation.

For a detailed study of this effect, we re-produced two of the samples shown in Fig. 2, namely the pure $\mathrm{ZnO}$ as a reference and a $3 \mathrm{~mol} \% \mathrm{Al}$ in the $\mathrm{ZnO}$ sample to represent the regime near maximal $\mathrm{Al}$ incorporation in $\mathrm{ZnO}$. The optical band gaps of these two samples are also shown in Fig. 2. They are shifted to higher energies relative to the samples prepared by Miao et al., but they reproduce the general trend of a narrower bandgap for the Al-doped sample quite well. The offset may be explained with differences in the preparation process or the particle size distribution. The XRD patterns of both samples showed only reflections due to the zincite phase, a wurtzitetype $\mathrm{ZnO}$ (PDF 36-1415, see ESI $\dagger$ ). The samples exhibit a slightly expanded unit cell volume, which is exclusively due to an increased $c$-axis compared to literature data (Table 1). For the $\mathrm{Al}$-containing sample, incorporation of $\mathrm{Al}$ in the $\mathrm{ZnO}$ lattice is confirmed by ${ }^{27} \mathrm{Al}-\mathrm{MAS}-\mathrm{NMR}$ data shown in Fig. 3. The spectrum is dominated by a narrow signal at a chemical shift of $81 \mathrm{ppm}$, which is assigned to $\mathrm{Al}$ in the well-defined tetrahedral environment of the $\mathrm{ZnO}$ lattice. ${ }^{18} \mathrm{It}$ is noted that a significant fraction of $\mathrm{Al}$ was also present in octahedral (signal at $7 \mathrm{ppm}$ ) and poorly defined five-fold coordination (signal near $46 \mathrm{ppm}^{33-35}$ ). These less well-defined $\mathrm{Al}$ species may be present in small amounts of X-ray amorphous Al-rich by-phases. For $\gamma-\mathrm{Al}_{2} \mathrm{O}_{3}$ the five-fold coordinated $\mathrm{Al}$ was associated with unsaturated surface species. ${ }^{36}$ The high field signal may also be due to $\mathrm{Al}$ residing on octahedral interstitial sites in $\mathrm{ZnO}$ or

Table 1 Selected characterization results of the $\mathrm{ZnO}$ materials with different $\mathrm{Zn}$ : Al ratios. Data for $\mathrm{ZnO}$ ref. were taken from PDF361415

\begin{tabular}{llllcl}
\hline $\mathrm{Zn}: \mathrm{Al}$ & $a / \AA$ & $c / \AA$ & $V / \AA^{3}$ & $\begin{array}{l}\mathrm{BET}-\mathrm{SA} / \\
\mathrm{m}^{2} \mathrm{~g}^{-1}\end{array}$ & $\begin{array}{l}\text { Optical } \\
\text { bandgap/eV }\end{array}$ \\
\hline $100: 0$ & $3.2505(3)$ & $5.2081(5)$ & $47.655(9)$ & 84 & 3.15 \\
$97: 3$ & $3.2500(3)$ & $5.2085(6)$ & $\begin{array}{l}47.645(12) \\
104\end{array}$ & 3.10 \\
$\mathrm{ZnO}$ ref. & 3.24982 & 5.20661 & 47.6216 & - & -
\end{tabular}




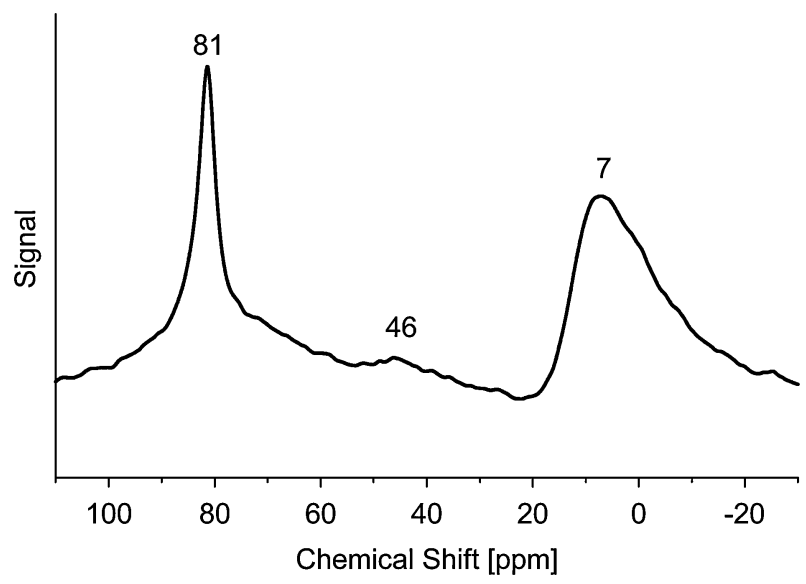

Fig. $3{ }^{27} \mathrm{Al}$-MAS-NMR spectrum of the $\mathrm{ZnO}$ sample containing $3 \mathrm{~mol} \% \mathrm{Al}$.

residues of the precursor material. TGA, XRD and NMR data can be found in the ESI. $\dagger$ We conclude that a significant fraction of the $\mathrm{Al}$ was incorporated into the $\mathrm{ZnO}$ phase and that the modification of the electronic structure observed for the sample series of Miao et al. was also present in our 3\% $\mathrm{Al}$ containing $\mathrm{ZnO}$ sample.

The morphology of the $\mathrm{ZnO}$ particles was investigated by TEM. The particle size distribution is shown in Fig. 4. The volume weighted average particle sizes are $14.42 \pm 0.08$ and
$9.94 \pm 0.07 \mathrm{~nm}$ for the pure $\mathrm{ZnO}$ and the Al-doped $\mathrm{ZnO}$, respectively. Similarly small particles of less than $15 \mathrm{~nm}$ are also present in industrial $\mathrm{Cu} / \mathrm{ZnO} / \mathrm{Al}_{2} \mathrm{O}_{3}$ methanol synthesis catalysts $^{22}$ (Fig. 1) supporting the idea that our samples are representative of the oxide phase in the composite catalyst. The Al-doped particles are significantly smaller compared to the pure $\mathrm{ZnO}$ reference material. Accordingly, the BET surface area of this sample is higher by $24 \%$ (Table 1 ). Thus, one effect of the presence of the Al-promoter in course of catalyst preparation is the hindrance of pronounced $\mathrm{ZnO}$ particle growth leading to larger specific surface areas.

According to their power spectra, all particles observed in the HRTEM images could be identified as belonging to the zincite phase. Also examples of the presence of two-dimensional defects in the $\mathrm{ZnO}$ lattice could be seen in some HRTEM images of both samples, indicating a rich defect chemistry which will evidently contribute to the electronic properties of the samples. A selection of locally observed defects like stacking faults or twin boundaries is shown in Fig. 5. Such planar defects are found normal to the [001] direction and affect the crystallographic $c$-axis. ${ }^{37-39}$ The expansion of this axis compared to literature data of $\mathrm{ZnO}$ (Table 1) suggests a higher concentration of these defects in the precipitated and calcined materials and is attributed to weaker bonding of the $\mathrm{Zn}-\mathrm{O}$ layers due to the presence of oxygen vacancies. It is noted that on basis of the ionic radii, one would expect an isotropic contraction of the $\mathrm{ZnO}$ lattice, if $\mathrm{Zn}$ is isomorphously substituted with $\mathrm{Al}$

a)
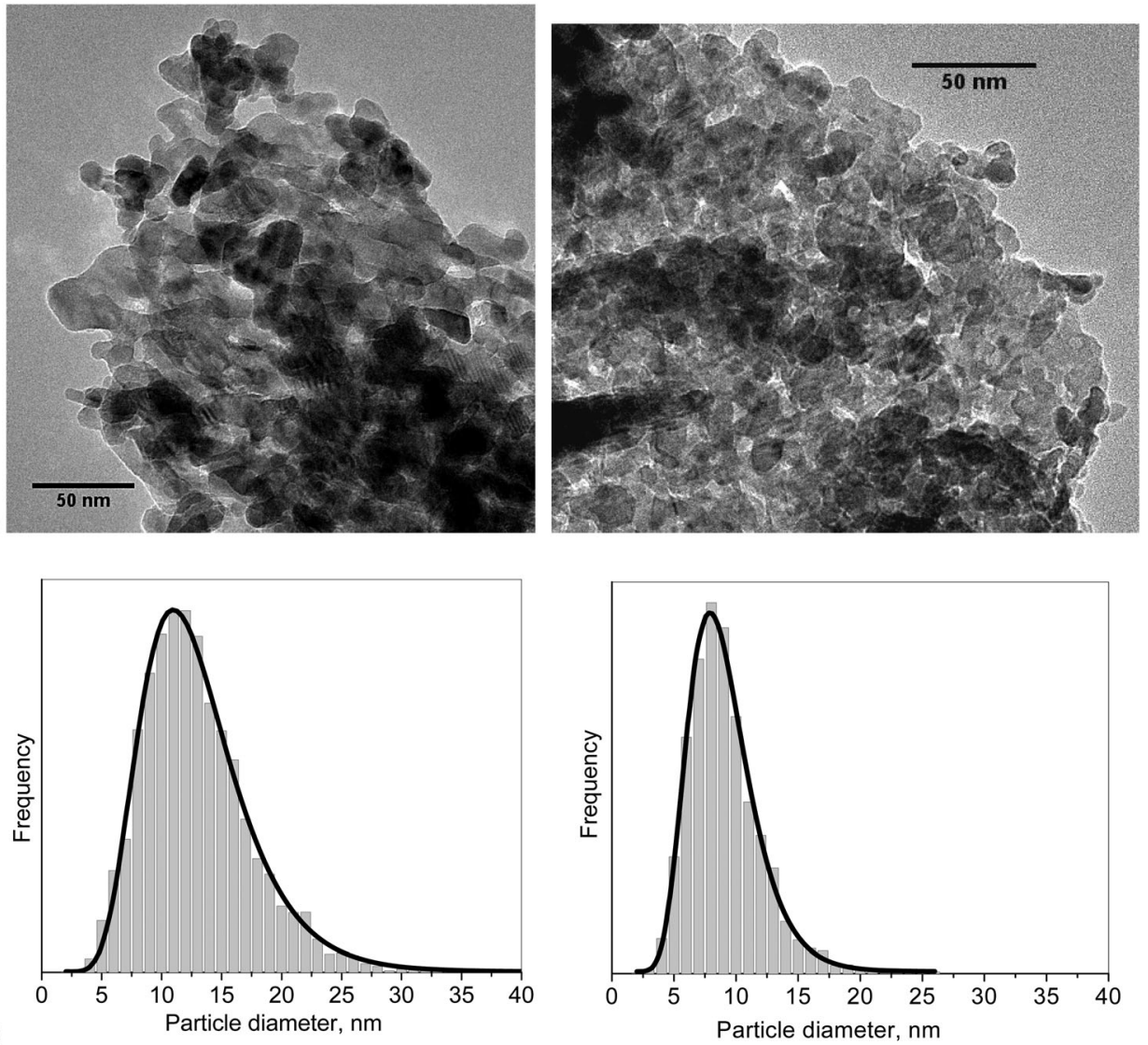

Fig. 4 (a) Representative TEM images of the $100: 0$ (left hand side) and the $97: 3$ (right hand side) Zn : Al samples; (b) particle size distributions determined for 3200 and 1600 particles, respectively, based on the projected particle areas measured in several TEM images of each sample. 


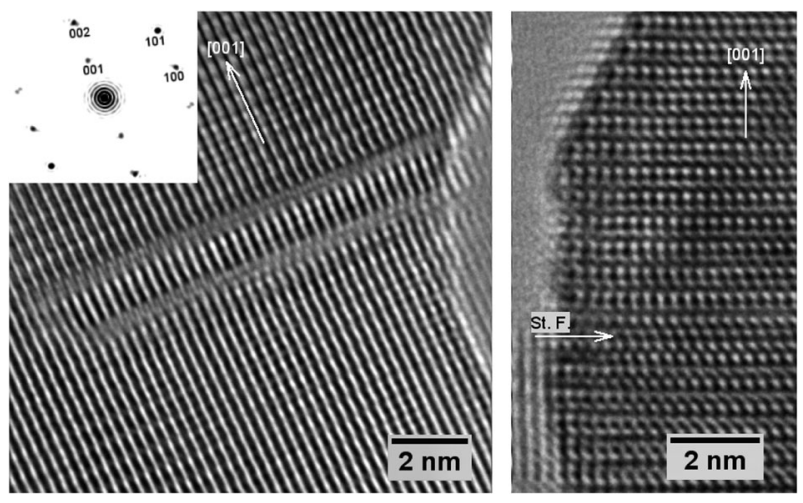

Fig. 5 HRTEM images of two $\mathrm{ZnO}$ crystals containing stacking faults normal to the [001] direction. Inset shows a power spectrum of a selected area in the left image.

(radii in a tetrahedral environment are 0.74 and $0.53 \AA$ for $\mathrm{Zn}^{2+}$ and $\mathrm{Al}^{3+}$, respectively ${ }^{40}$ ). The absence of a significant lattice contraction despite the $\mathrm{Al}$ incorporation seen in the Al-NMR data may be a result of the high defect density of the Al-doped material. Moreover, the appearance of the 001 peak in HRTEM power spectra (Fig. 5), which should be systematically absent in the perfect wurtzite structure, indicates the presence of oxygen vacancies preferentially in every second oxygen layer normal to [001]. ${ }^{41}$

It can be concluded that the applied preparation of $\mathrm{ZnO}$ leads to defective and nano-structured samples. Furthermore, the modified electronic structure of Al-containing $\mathrm{ZnO}$ is associated with a unique defect structure as $\mathrm{Al}_{\mathrm{Zn}}$ is also present in addition to the typical point defects in $\mathrm{ZnO}, \mathrm{V}_{\mathrm{O}}$ and $\mathrm{Zn}_{i}$. The particle size of the Al-doped sample is smaller, while planar defects were found to be present in both samples.

In order to better understand the role of defects in $\mathrm{ZnO}$ on catalysis, we addressed the question, whether these modifications are stable under conditions relevant for catalytic methanol synthesis, i.e. in a reducing atmosphere at mild temperatures around $250{ }^{\circ} \mathrm{C}$. This question was studied using several complementary in situ techniques: UV-vis, XPS and NEXAFS spectroscopy. EPR and NMR were used as complementary ex situ characterization tools.

During the in situ UV-vis experiment, the samples were exposed to a reducing atmosphere $\left(1\right.$ bar $\left.\mathrm{H}_{2}, 250{ }^{\circ} \mathrm{C}\right)$ for a prolonged time and absorption spectra were recorded. These results are shown in Fig. 6. In accordance with the ex situ measurements shown in Fig. 2, the band gap energy is significantly lower for the Al-modified sample.

Considering that the electronic properties (electron and hole mobility and energy levels) are affected by temperature, an initial heating cycle from room temperature to $250{ }^{\circ} \mathrm{C}$ in an inert atmosphere (holding for 30 min followed by cooling) had been done to distinguish between the thermal effects and the one induced by $\mathrm{H}_{2}$ exposure. This is shown in the leftmost part of Fig. 6. A decrease of the band gap energy of approximately $60 \mathrm{meV}$, common to both samples, was followed by a complete recovery of the original band gap energy after cooling. Thus the samples were not permanently affected by heating, as can be expected, since they were originally calcined at $320{ }^{\circ} \mathrm{C}$ in air. The decrease of $60 \mathrm{meV}$ is mainly associated with the

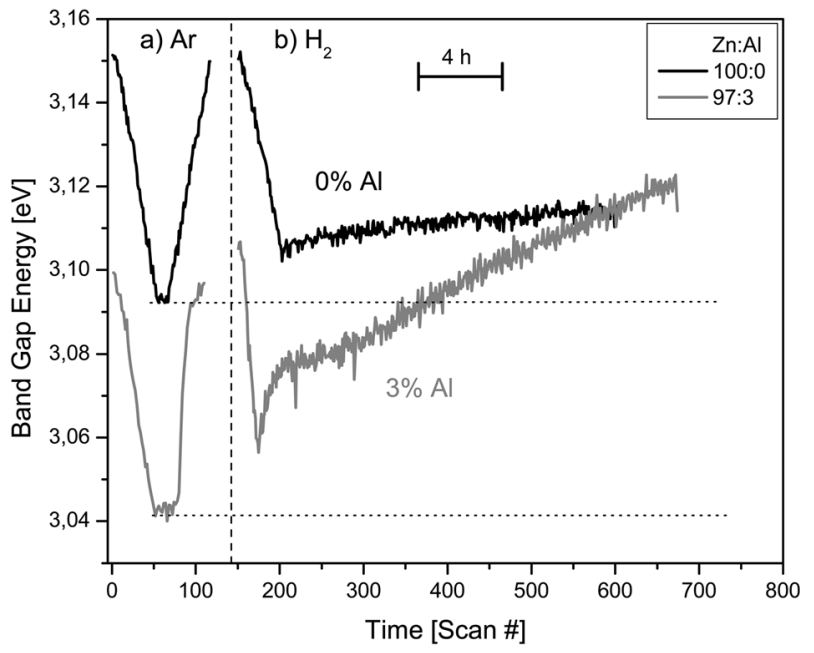

Fig. 6 Optical bandgap energies of the doped and undoped samples determined from in situ UV-vis data during heating in $\mathrm{Ar}$ (a) and treatment in a reducing $\mathrm{H}_{2}$ atmosphere at $250{ }^{\circ} \mathrm{C}$ (b).

thermal excitation of the electrons and holes: considering $\Delta T=230 \mathrm{~K}$ (from 20 to $250{ }^{\circ} \mathrm{C}$ ) the value $\Delta E=2 k_{\mathrm{B}} \Delta T \cong$ $40 \mathrm{meV} .{ }^{29}$ The factor 2 arises from the reciprocal excitation of electrons (up) and holes (down) upon widening of the valence and conduction band of the semiconductor. The difference between the calculated and observed values of $20 \mathrm{meV}$, respectively, can be accounted for by an additional change in band energy due to thermal expansion of the lattice. ${ }^{29}$

In the presence of $\mathrm{H}_{2}$ (1 bar - right hand part of Fig. 6), a deviation of the band gap energy from the expected value at $250{ }^{\circ} \mathrm{C}$ (dotted line) is observed for both samples. It increases nearly linearly with time for the pure $\mathrm{ZnO}$ support. This change in the electronic structure is relatively slow and can most likely be attributed to an annealing effect changing in the density of defect donor sites. ${ }^{42,43}$ No stable state is reached after $20 \mathrm{~h}$ on stream.

A completely different behavior is shown by the sample with $3 \% \mathrm{Al}$ : an initially rapid increase in the band gap energy is observed during the first 2 hours of contact with $\mathrm{H}_{2}$ followed by a slower but still marked increase in the remaining time. After a time on stream of approximately $15 \mathrm{~h}$ the values of both samples are identical. These results indicate that the modifications of the electronic and defect structure of $\mathrm{ZnO}$ by $\mathrm{Al}$ incorporation are not stable in reducing environments such as applied in many catalytic reactions. The band gap energy rapidly becomes similar to a non-doped sample. It is likely that this effect is related to a restructuring of the $\mathrm{Al}$ ions in the $\mathrm{ZnO}$ lattice and thus interesting to study this bulk-effect with surface sensitive and Al-specific methods.

By means of environmental XPS, we have investigated the changes in surface composition associated with the increase in band gap energy of the Al-modified sample in a reducing atmosphere. Reference spectra were collected at 0.2 mbar $\mathrm{Ar}$ pressure at room temperature. Then the samples were studied in a reductive atmosphere in 1 mbar of $\mathrm{H}_{2}$ and gradually heated to $250{ }^{\circ} \mathrm{C}$ and held there for $10 \mathrm{~h}$.

Fig. 7 shows the surface and near surface composition as a function of temperature and time. The $\mathrm{Zn}$ : Al ratio detected 


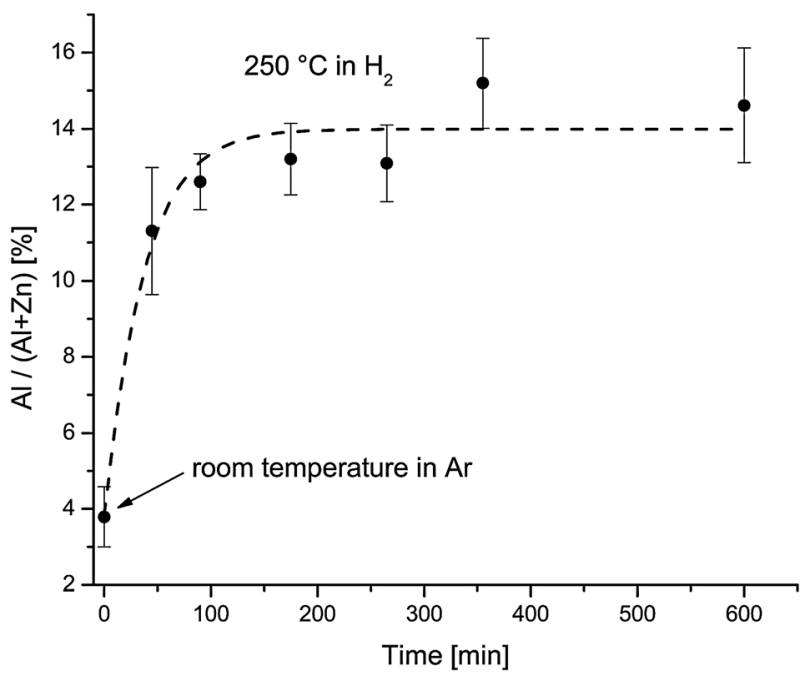

Fig. 7 Surface $\mathrm{Zn}$ : Al ratio determined from the core level XP spectra of the Al-doped $\mathrm{ZnO}$ sample during heating to $250{ }^{\circ} \mathrm{C}$ in $\mathrm{H}_{2}$ and holding at that temperature.

at room temperature in $\mathrm{Ar}$ was very close to the expected $97: 3$ ratio indicating the homogeneous distribution of $\mathrm{Al}$ in the calcined material. Upon reducing treatment, however, a pronounced migration of $\mathrm{Al}$ towards the surface is observed. After exposure to $\mathrm{H}_{2}$ for $10 \mathrm{~h}$ the $\mathrm{Zn}$ : Al ratio was lowered to 86 : 14. Considering that the effect of $\mathrm{H}_{2}$ can only be a partial reduction resulting in increased density of $\mathrm{O}$ vacancies near the surface, these likely represent the driving force of the migration process of $\mathrm{Al}$ ions towards the surface. These vacancies will also possibly stabilize the surface creating an $\mathrm{Al}$ rich region, with a more ionic "alumina-like" character.

To characterize the environment around the dynamic Al atoms we have performed Al K-edge NEXAFS measurements, using the same synchrotron setup in a total electron yield configuration. The spectra before and after exposure to $\mathrm{H}_{2}$ are shown in Fig. 8. Following Shimizu et al., ${ }^{44}$ we can assign signals in the edge region $(1560-1575 \mathrm{eV})$ that carry information about the coordination and the environment around the $\mathrm{Al}$ site, to estimate the ratio between tetrahedral and octahedral Al sites. $^{45-48}$ In particular an absorption feature at $1565 \mathrm{eV}$ is associated uniquely with $\mathrm{Al}$ in tetrahedral coordination, while a second resonance at $1567 \mathrm{eV}$ is associated uniquely with $\mathrm{Al}$ in octahedral coordination. ${ }^{48}$ Another broad band at $1571 \mathrm{eV}$ includes multiple scattering contributions but is associated mainly with octahedral Al ${ }^{46,47}$ In our data it was not possible to resolve the two separate peaks at 1565 and $1567 \mathrm{eV}$ and we are limited to a simple qualitative evaluation of the relative intensities. The contribution due to tetrahedrally coordinated Al clearly increases relative to the fraction of octahedral Al as indicated by the change in the intensity ratio of the two signals at the absorption edge seen in Fig. 8. Considering that this effect is associated with the migration of $\mathrm{Al}$ to the surface, one can suppose that this different NEXAFS spectrum is related to an enrichment of $\mathrm{Al}_{\mathrm{Zn}}$ at the surface of $\mathrm{ZnO}$, because a surface phase segregation would rather result in formation of alumina phases, which usually contain a larger fraction of octahedrally coordinated $\mathrm{Al}$. This is also in qualitative agreement with ex situ Al-NMR spectra recorded after exposure to $\mathrm{H}_{2}$ (see ESI $\dagger$ ), in

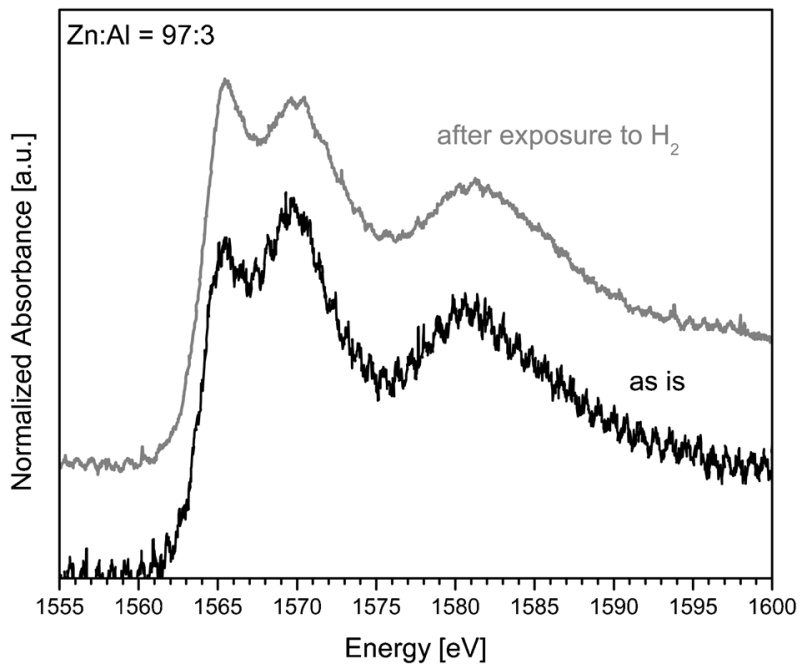

Fig. 8 Al-K NEXAFS spectra of the Al-doped $\mathrm{ZnO}$ sample before and after $\mathrm{H}_{2}$ exposure at $250{ }^{\circ} \mathrm{C}$.

which the relative ratio of octahedrally and tetrahedrally coordinated $\mathrm{Al}$ does not show a pronounced change, while the signals due to five-fold coordinated Al, likely to be present at the surface of the sample, show a slight increase.

It can be concluded that exposure to $\mathrm{H}_{2}$ at mild temperatures leads to a re-distribution of $\mathrm{Al}$ in the Al-modified sample, while the defect structure of pure $\mathrm{ZnO}$ is less affected. The Al-depletion of the bulk leads to similar bad gap energies of both samples after reducing treatment. In the near surface region an Al-enriched shell around the particles is formed. This enrichment, thus, seems to be due to migration of $\mathrm{Al}$ located on the tetrahedral sites of the $\mathrm{ZnO}$ lattice towards the surface. Despite the high concentration at the surface, Al still predominantly occupies these sites after $\mathrm{H}_{2}$ exposure in the newly formed shell.

A very sensitive method for characterization of defects in $\mathrm{ZnO}$ is EPR spectroscopy. Even in undoped $\mathrm{ZnO}$ materials it is common to find a paramagnetic feature around $g \cong$ $1.96,,^{2,42,43}$ which is also typical for n-type doped materials ${ }^{49,50}$ and is due to a $\mathrm{Zn} / \mathrm{O}$ imbalance towards the cation $\mathrm{Zn}^{+/ 2+}$. In principle, this can be either due to an excess of $\mathrm{Zn}$ (e.g. interstitial $\mathrm{Zn}^{+}$) or lack of $\mathrm{O}\left(\right.$ e.g. vacant $\mathrm{O}^{2-}$ ). A more detailed discussion of the EPR features of defective $\mathrm{ZnO}$ can be found $e . g$. in ref. 11 , where the signal at $g \cong 1.96$ is assigned to shallow donor sites.

The EPR spectra of our two samples after different heat treatments are shown in Fig. 9. In both samples a narrow EPR signal $\left(\Delta B_{\mathrm{pp}}=0.6 \mathrm{mT}\right)$ is observed at $g=1962( \pm 0.0005)$ already after calcination, confirming the defective nature of $\mathrm{ZnO}$. While upon heating in $\mathrm{He}$ a severe broadening and a slight shift of the signal $(g=1963: \Delta=0.001)$ are observed for both samples, drastic differences are observed under $\mathrm{H}_{2}$ exposure. In the case of the pure $\mathrm{ZnO}$ sample, only a further broadening of the EPR line, but no further shift is detected in agreement with the stable band gap energy (Fig. 6). In the spectra of the Al-modified sample, however, a very pronounced further broadening of the paramagnetic signal $\left(\Delta B_{\mathrm{pp}}: 0.6 \mathrm{mT} \rightarrow\right.$ $1.4 \mathrm{mT} \rightarrow 1.9 \mathrm{mT}$ ) is accompanied by a breakdown of the amplitude upon reducing treatment. The EPR line is, moreover, significantly shifted to higher $g$-values $(1.963 \rightarrow 1.965 \rightarrow 1.966)$. 


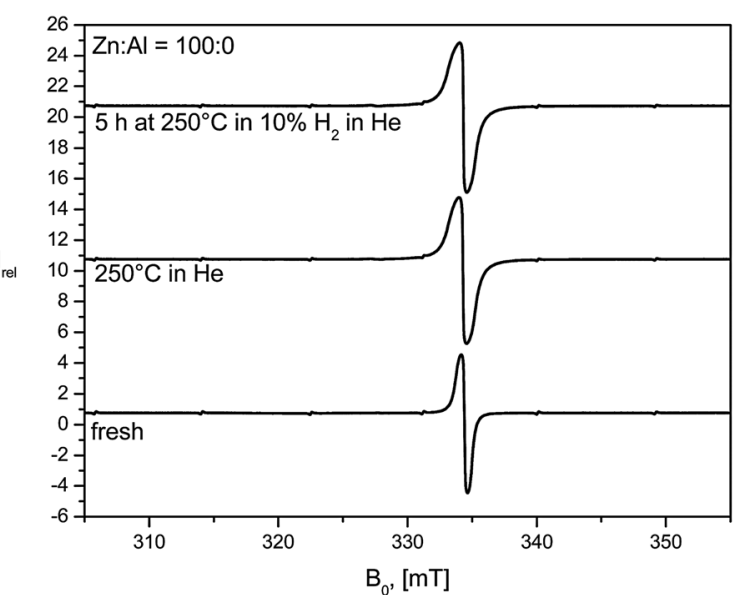

a)

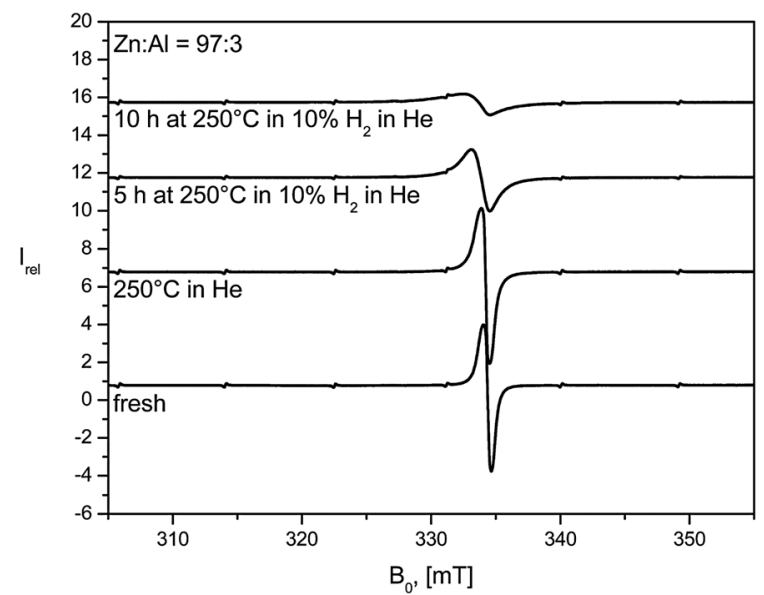

Fig. 9 EPR spectra of the undoped (a) and doped (b) $\mathrm{ZnO}$ samples recorded after calcination, after heating to $250{ }^{\circ} \mathrm{C}$ in $\mathrm{He}$, and after prolonged treatment at $250{ }^{\circ} \mathrm{C}$ in $\mathrm{H}_{2} / \mathrm{He}$. The curves are vertically offset for clarity.

At a first sight, this result is in good accordance with the pronounced changes in band gap energy and the dynamics in the $\mathrm{Al}$ distribution. However, further experiments are clearly needed in order to obtain more insight into the mechanism of defect re-structuring in the $\mathrm{Al}$-doped $\mathrm{ZnO}$ sample.

The EPR results finally confirmed that the defect chemistry of $\mathrm{ZnO}$ is substantially affected by the incorporation of the $\mathrm{Al}$ promoter. Treatment of this modified defect structure under catalytically relevant conditions leads to a complex reconstruction of the defect donor sites in the material, which is associated with the segregation of $\mathrm{Al}$ ions at the surface of the $\mathrm{ZnO}$ nanoparticles.

On basis of the results of this model study, it can be speculated that the promoting effect of $\mathrm{Al}$ in the $\mathrm{Cu} / \mathrm{ZnO} /$ $\mathrm{Al}_{2} \mathrm{O}_{3}$ system is not necessarily due to modification of the electronic structure of $\mathrm{ZnO}$ phase by $\mathrm{Al}$ incorporation into the oxide lattice, which was detected in ex situ experiments, but that the doped system may rather act as a precursor for the promoted support phase formed under reaction conditions. In a reducing atmosphere, the $\mathrm{Al}$ dopant migrates towards the surface of the $\mathrm{ZnO}$ stabilizer particles and modifies their surface properties. The timescale of this process is on the order of several hours and it thus happens in the formation period of the ternary catalyst. Following this hypothesis, the modified surface of the oxide phase may not only affect the "synergetic" $\mathrm{Cu}-\mathrm{ZnO}$ interactions (i.e. surface alloy formation by SMSI $^{7,51}$ or wetting-de-wetting effects ${ }^{52}$ causing transient changes in catalytic activity on a short timescale ${ }^{53}$ ), but also the mobility of the supported $\mathrm{Cu}$ particles avoiding catalyst deactivation by sintering, which usually happens on a much longer timescale and is considered one of the main reasons for deactivation of $\mathrm{Cu}$-based catalysts. ${ }^{54}$

\section{Conclusions}

In summary, $\mathrm{Al}$-free and $\mathrm{Al}$-containing $\mathrm{ZnO}$, which resembles the oxide component in binary or ternary $\mathrm{Cu} / \mathrm{ZnO} /\left(\mathrm{Al}_{2} \mathrm{O}_{3}\right)$ methanol synthesis catalysts, respectively, was synthesized in the form of nanoparticles by (co-)precipitation and characterized using various methods. The $\mathrm{ZnO} / \mathrm{Al}_{2} \mathrm{O}_{3}$ system initially exhibits homogenous doping of the $\mathrm{ZnO}$ phase by $\mathrm{Al}$ at low $\mathrm{Al}$ contents. This doping reduces the band gap energy and leads to a defect rich material of small particle size. Under reducing conditions, however, the defect structure is unstable and Al migration towards the surface of the $\mathrm{ZnO}$ particles is observed, but no segregation of alumina phases seems to happen. The band gap energy also changes and evolves towards the value observed for the Al-free support, which is also defective, but more stable in reducing conditions.

\section{Acknowledgements}

The help of Gisela Lorenz (BET), Edith Kitzelmann (XRD) and Steffi Kühl (XPS) with sample characterization is acknowledged. We thank Nur Fadilah Idris and Sharifah Bee Abd Hamid for recording the NMR spectra and BESSY for allocation of synchrotron measurement time. Thomas Risse is acknowledged for fruitful discussions. Part of the work was funded by the German Federal Ministry of Education and Research, BMBF (No. 01RI0529).

\section{References}

1 K. Ueda, H. Tabata and T. Kawai, Appl. Phys. Lett., 2001, 79, 988.

2 Ü. Özgür, Y. Alivov, C. Liu, A. Teke, M. Reshchikov, S. Dogan, V. Avrutin, S. Cho and H. Morkoc, J. Appl. Phys., 2005, 98, 041301 .

3 R. Cebulla, R. Wendt and K. Ellmer, J. Appl. Phys., 1998, 83, 1087.

4 Z. W. Pan, Z. R. Dai and Z. L. Wang, Science, 2001, 291, 1947.

5 S. Kaluza, M. K. Schröter, R. Naumann d'Alnoncourt, T. Reinecke and M. Muhler, Adv. Funct. Mater., 2008, 18, 3670.

6 Ch. Wöll, Prog. Surf. Sci., 2007, 82, 55.

7 J. Grunwaldt, A. Molenbroek, N. Topsøe, H. Topsøe and B. Clausen, J. Catal., 2000, 194, 452.

8 M. Spencer, Top. Catal., 1999, 8, 259.

9 K. Jung, O. Joo and S. Han, Catal. Lett., 2000, 68, 49.

10 S. Polarz, J. Strunk, V. Ischenko, M. W. E. van den Berg, O. Hinrichsen, M. Muhler and M. Driess, Angew. Chem., Int. Ed., 2006, 45, 2965.

11 V. Ischenko, S. Polarz, D. Grote, V. Stavarache, K. Fink and M. Driess, Adv. Funct. Mater., 2005, 15, 1945.

12 M. Salmeron and R. Schlögl, Surf. Sci. Rep., 2008, 63, 169.

13 M. Behrens, F. Studt, I. Kasatkin, S. Kühl, M. Hävecker, F. AbildPedersen, S. Zander, F. Girgsdies, P. Kurr, B.-L. Kniep, M. Tovar, R. W. Fischer, J. K. Nørskov and R. Schlögl, Science, 2012, 336, 893.

14 R. Revel, D. Banzin, E. Elkaim, Y. Khin and H. Dexpert, J. Phys. Chem. B, 2000, 104, 9828 . 
15 D. Bazin and J. Rehr, Catal. Lett., 2003, 87, 85.

16 M. Yang, S. Li and G. Chen, Appl. Catal., B, 2011, 101, 409.

17 R. G. S. Pala, W. Tang, M. M. Sushchikh, J.-N. Park, A. J. Forman, G. Wu, A. Kleinman-Sharsctein, J. Zhang, E. W. McFarland and H. Metiu, J. Catal., 2009, 266, 50.

18 S. Miao, R. N. d'Alnoncourt, T. Reinecke, I. Kasatkin, M. Behrens, R. Schlögl and M. Muhler, Eur. J. Inorg. Chem., 2009, 7, 910.

19 M. Behrens and F. Girgsdies, Z. Anorg. Allg. Chem., 2010, 636, 2087.

20 M. Behrens, J. Catal., 2009, 267, 24.

21 P. Kurr, I. Kasatkin, F. Girgsdies, A. Trunschke, R. Schlögl and T. Ressler, Appl. Catal., A, 2008, 348, 153.

22 I. Kasatkin, P. Kurr, B. Kniep, A. Trunschke and R. Schlögl, Angew. Chem., 2007, 119, 7465.

23 D. Waller, D. Stirling, F. S. Stone and M. S. Spencer, Faraday Discuss. Chem. Soc., 1989, 87, 107.

24 A. A. Coelho, Topas, General Profile and Structure Analysis Software for Powder Diffraction Data, Version 3.0, Bruker AXS GmbH, Karlsruhe, Germany, 2006.

25 R. Weber, J. Catal., 1995, 151, 470.

26 A. Khodakov, B. Olthof, A. Bell and E. Iglesia, J. Catal., 1999, 181, 205.

27 K. Chen, A. Bell and E. Iglesia, J. Catal., 2002, 209, 35.

28 D. G. Barton, M. Shtein, R. D. Wilson, S. L. Soled and E. Iglesia, J. Phys. Chem. B, 1999, 103, 630.

29 R. A. Smith, Semiconductors, Cambridge University Press, 2nd edn, 1978.

30 A. Knop-Gericke, E. Kleimenov, M. Hävecker, R. Blume, D. Teschner, S. Zafeiratos, R. Schlögl, V. I. Bukhtiyarov, V. V. Kaichev, I. P. Prosvirin, A. I. Nizovskii, H. Bluhm, A. Barinov, P. Dudin and M. Kiskinova, Adv. Catal., 2009, 52, 213.

31 H. Bluhm, M. Havecker, A. Knop-Gericke, M. Kiskinova, R. Schlögl and M. Salmeron, MRS Bull., 2007, 32, 1022.

32 J. Yeh and I. Lindau, At. Data Nucl. Data Tables, 1985, 32, 1.

33 N. Nava, P. Salas, M. Llanos, H. Pérez-Pastenes and T. Viveros, Hyperfine Interact., 2005, 161, 11.

34 S. Risbud, R. Kirkpatrick, A. Taglialavore and B. Montez, J. Am. Ceram. Soc., 1987, 70, 10.
35 J. Stebbins, S. Kroeker, S. Keun Lee and T. Kiczenski, J. NonCryst. Solids, 2000, 275, 1.

36 C. Pecharromán, I. Sobrados, J. E. Iglesias, T. González-Carreno and J. Sanz, J. Phys. Chem. B, 1999, 103, 6160.

37 Y. Ding and Z. L. Wang, Micron, 2009, 40, 335.

38 V. Potin, P. Ruterana and G. Nouet, J. Phys.: Condens. Matter, $2000,12,10301$.

39 C. Stampfl and C. G. Van de Walle, Phys. Rev. B: Condens. Matter Mater. Phys., 1998, 57, R15052.

40 R. D. Shannon, Acta Crystallogr., Sect. A: Cryst. Phys., Diffr., Theor. Gen. Crystallogr., 1976, 32, 751.

41 V. Roddatis, E. Stepantsov and N. Kiselev, J. Cryst. Growth, 2000, $220,515$.

42 P. H. Kasai, Phys. Rev., 1963, 130, 989.

43 K. Vanheusden, C. H. Seager, W. L. Warren, D. R. Tallant and J. A. Voigt, Appl. Phys. Lett., 1996, 68, 403.

44 K. Shimizu, Y. Kato, H. Yoshida, A. Satsuma, T. Hattori and T. Yoshida, Chem. Commun., 1999, 1681.

45 D. Li, G. Bancroft, M. Fleet, X. Feng and Y. Pan, Am. Mineral., $1995, \mathbf{8 0}, 432$.

46 D. Cabaret, P. Sainctavit, P. Ildefonse and A. Flank, J. Electron Spectrosc. Relat. Phenom., 1996, 79, 21.

47 D. Cabaret, E. Gaudry, M. Taillefumier, P. Sainctavit and F. Mauri, Phys. Scr., 2005, 115, 131.

$48 \mathrm{~J}$. van Bokhoven, A. van der Eerden and D. Koningsberger, J. Am. Chem. Soc., 2003, 125, 7435.

49 S. Moribe, T. Ikoma, K. Akiyama, Q. Zhang, F. Saito and S. TeroKubota, Chem. Phys. Lett., 2007, 436, 373.

50 N. Garces, L. Wang, L. Bai, N. Giles, L. Halliburton and G. Cantwell, Appl. Phys. Lett., 2002, 81, 622.

51 R. Naumann d'Alnoncourt, X. Xia, J. Strunk, E. Löffler, O. Hinrichsen and M. Muhler, Phys. Chem. Chem. Phys., 2006, 13, 1525.

52 C. V. Ovesen, B. S. Clausen, J. Schiøtz, P. Stoltze, H. Topsøe and J. K. Nørskov, J. Catal., 1997, 168, 133.

53 P. C. K. Vesborg, I. Chorkendorff, I. Knudsen, O. Balmes, J. Nerlov, A. M. Molenbroek, B. S. Clausen and S. Helveg, J. Catal., 2009, 262, 65.

54 M. V. Twigg and M. S. Spencer, Top. Catal., 2003, 22, 191. 